\title{
Relationship between Cortisol Responses to Stress and Personality
}

\author{
Lynn M Oswald ${ }^{1,2}$, Peter Zandi ${ }^{3}$, Gerald Nestadt', James B Potash', Amanda E Kalaydjian ${ }^{3}$ \\ and Gary S Wand ${ }^{*, 1,4}$
}

'Department of Psychiatry, The Johns Hopkins University School of Medicine, Baltimore, MD, USA; ${ }^{2}$ University of Maryland School of Nursing, Baltimore, MD, USA; ${ }^{3}$ Bloomberg School of Public Health, Baltimore, MD, USA; ${ }^{4}$ Department of Medicine, The Johns Hopkins University School of Medicine, Baltimore, MD, USA

\begin{abstract}
Although there is growing evidence of links between the cortisol stress response and personality, the nature of the relationships and the underlying mechanisms require further clarification. The purpose of this study was to examine associations between personality traits and cortisol responses to stress using the Revised NEO Personality Inventory five-factor model of personality. In total, 68 healthy adults, aged 18-30 years, completed the personality assessment and underwent a laboratory psychological stress test that consisted of a 5 min speech and 5-min of mental arithmetic. Findings showed that in the sample as a whole, less Openness was associated with lower cortisol responses to the challenge. Cortisol responses also corresponded to certain personality dimensions in a gender-specific manner. Blunted cortisol responses were associated with higher Neuroticism in women and with lower Extraversion in men. These findings suggest that personality traits that have been traditionally associated with greater psychopathology were also associated with blunted HPA axis responses to stress.

Neuropsychopharmacology (2006) 3 I, | 583-159I. doi:I 0. I038/sj.npp. I 30 I0 I2; published online II January 2006
\end{abstract}

Keywords: cortisol; personality; affective illness; NEO PI-R

\section{INTRODUCTION}

It is well established that mood disorders are often associated with alterations in hypothalamic-pituitaryadrenal (HPA) axis function (Holsboer, 2000; Owens and Nemeroff, 1993; Young et al, 2004). Although some studies have found no alterations in HPA axis activity in major depression, evidence of hypercortisolism is one of the most consistent biological findings among psychiatric patients (Carroll, 1982; Holsboer and Barden, 1996; Linkowski, 2003; Young et al, 2000). Recent research further suggests that different diagnostic subtypes of depression may be characterized by different types of stress system pathology. Specifically, it has been suggested that melancholic depression is associated with HPA axis hyperactivity, whereas atypical depression is associated with HPA axis downregulation (Anisman et al, 1999; Geracioti et al, 1997; Gold and Chrousos, 2002). Findings of HPA axis dysregulation in

\footnotetext{
*Correspondence: Dr GS Wand, Department of Psychiatry, The Johns Hopkins University School of Medicine, Ross Research Building, Room 863, 720 Rutland Avenue, Baltimore, MD 21205, USA, Tel: + I 410 955 7225, Fax: + I 410955 084I, E-mail: gwand@jhmi.edu Received 22 July 2005; revised 29 September 2005; accepted 7 November 2005

Online publication: 22 November 2005 at http://www.acnp.org/ citations/Npp I | 2205050468/default.pdf
}

patients with primary anxiety disorders are generally less robust than in those with major depression (Arborelius et al, 1999; Young et al, 2004). However, HPA axis hyperactivity has been documented in studies of social phobia (Furlan et al, 2001), panic disorder (Abelson and Curtis, 1996; Coryell et al, 1991; Roy-Byrne et al, 1986; Schreiber et al, 1996; Wedekind et al, 2000), generalized anxiety (Roy-Byrne et al, 1986), obsessive-compulsive disorder (Altemus et al, 1992), and mixed anxietydepressive disorder (Kara et al, 2000). In contrast, patients with post-traumatic stress disorder show evidence of decreased basal cortisol levels and increased negative feedback regulation of the HPA axis as compared to normal controls (Yehuda, 1997).

Although dysregulation of stress hormones was originally thought to be an epiphenomenon of mood disorders, a growing database suggests that excess cortisol secretion may contribute to the mood symptoms, in part, by increasing CRH expression in the amygdala and other key brain regions (Holsboer, 2000; Tsigos and Chrousos, 2002). There is evidence that neuroendocrine dysregulation often normalizes with antidepressant treatment and that a lack of normalization may be associated with early relapse (Arborelius et al, 1999; Barden, 2004; Holsboer, 2000). Furthermore, nonaffected family members of depressed probands often have abnormal HPA axis function, suggesting 
that glucocorticoid abnormalities may represent genetic vulnerability factors that predispose to and/or exacerbate the course of mood disorders (Modell et al, 1998).

Paralleling the association of glucocorticoid abnormalities and mood disorders is evidence that specific personality traits are more common in patients with depression or anxiety than in individuals without these conditions. For example, neuroticism, extraversion, and facets of agreeableness and conscientiousness have been linked to depression and/or anxiety disorders in the general population (Bienvenu et al, 2001, 2004; Samuels et al, 2002). Specifically, neuroticism has been associated with social phobia, agoraphobia, panic disorder, obsessive-compulsive disorder, and major depression; introversion has been associated with social phobia and agoraphobia. Facets of agreeableness appear relevant to phobias, and facets of conscientiousness appear relevant to phobic, panic, and major depressive disorders (Bienvenu et al, 2004). Similar to abnormalities in the HPA axis, these personality traits have been posited to predispose to mood disorders (Hirschfeld et al, 1989), although the relationships appear complex (Kendler et al, 1993).

Whereas aberrant cortisol dynamics and personality traits have each been closely linked to mood disorders, it remains uncertain whether there is a relationship between the glucocorticoid stress response and personality traits. Findings from several studies that have attempted to uncover relationships between these variables have been inconsistent (Pruessner et al, 1997). Traits that have been investigated have included anxiety (Hubert and Jong-Meyer, 1992; Jezova et al, 2004; Salmon et al, 1989; van Eck et al, 1996), sensation seeking (Kirschbaum et al, 1992), extraversion, and neuroticism (Arnetz and Fjellner, 1986; LeBlanc and Ducharme, 2005; Phillips et al, 2005; Schommer et al, 1999). Many of these studies were conducted with instruments that measure 'higher-order' personality dimensions, which actually encompass groups of more specific, but highly intercorrelated traits. It may be necessary to define personality more precisely in order to capture relationships with cortisol responses to stress; further evaluation of gender effects on these relationships is also warranted. In this study, we used the Revised NEO Personality Inventory (Costa and McCrae, 1992) to examine relationships between personality and responses to a laboratory psychological stress test. The NEO was developed to operationalize five factors that represent the most basic dimensions of personality that have been identified in natural languages and in psychological questionnaires; each of the five factors is further differentiated into six specific facets.

\section{MATERIALS AND METHODS}

\section{Subjects}

A total of 68 healthy adults, aged 18-30 years, were recruited by newspaper advertisements and posted flyers from the Baltimore area. Persons who appeared to qualify for research participation based on a telephone screen were invited to the laboratory for an interview. After complete description of the study, volunteers provided written informed consent, approved by the Johns Hopkins Medi- cine Institutional Review Board. Subject assessment included a medical history and physical examination, blood chemistry profile, complete blood count, electrocardiogram, urinalysis, alcohol breathalyzer test, and urine toxicology screen. The Semi-Structured Assessment for the Genetics of Alcoholism (Bucholz et al, 1994) was administered by a Master's level interviewer to identify DSM-IV axis I psychiatric diagnoses. Exclusion criteria included: (a) current medical conditions and/or use of prescription medications, (b) presence of a DSM-IV axis I disorder, including alcohol/drug dependence or abuse, (c) use of any psychoactive medications within the past 30 days, (d) treatment in the last 6 months with antidepressants, neuroleptics, sedative hypnotics, glucocorticoids, appetite suppressants, estrogens, opiate, or dopamine medications, (e) seizure disorder or history of closed head trauma, (f) report drinking more than 30 drinks per month, $(\mathrm{g})$ unable to provide clean urine drug screens at intake or during study participation, and (h) pregnancy or lack of effective nonhormonal methods of birth control in females. Female subjects were tested in the follicular phase of their menstrual cycle. One subject smoked cigarettes, approximately 6 per day.

\section{Trier Social Stress Test (TSST)}

Subjects reported to the study room at $1200 \mathrm{~h}$ to undergo a modified version of the TSST (Kirschbaum et al, 1993); they were fasting since $1000 \mathrm{~h}$ and were instructed to refrain from use of any alcohol, illicit drugs, or over the counter medications for $48 \mathrm{~h}$ prior to participation. An intravenous catheter was placed in a forearm vein at $1215 \mathrm{~h}$ for blood sampling and subjects were secured to a pressure cuff, which recorded vital signs. Baseline blood samples, heart rate, and blood pressure readings were obtained at 1200 , 1215 , and $1230 \mathrm{~h}$. Subjects then listened to audio-taped instructions of the performance task. In these instructions, they were told that they would be taking on the role of a job applicant for the position of hospital administrator and, in a 5 -min speech, should convince a panel of interviewers that they were the best candidates for the job. They were also told that, immediately following the speech, they would be asked to perform a 5-min oral mental arithmetic challenge that would be judged on speed and accuracy. They were given 10 min to mentally prepare for the task, after which they were escorted to another room and instructed to stand at the end of a long table with two interviewers sitting at the other end. One of the interviewers asked the subject to describe his/her qualifications for the job, while another began operating a video camera. Subjects were expected to utilize the entire $5 \mathrm{~min}$ for the speech and were prodded as needed by the interviewers. At the completion of the speech, subjects were given instructions for the mental arithmetic task. They were told to repeat a four-digit number after the interviewer, subtract 13 from it, and call out their answer. If a mistake was made, the subject was prompted to start again from the beginning. At the end of the mental arithmetic task, subjects were escorted back to the study room, where they were asked to sit quietly for the remainder of the protocol. Immediately after the arithmetic task and at 15min intervals, five additional blood specimens were withdrawn and blood pressure and heart rate were recorded. 


\section{Psychometric Instruments}

Subjects completed self-report measures of personality, psychological distress, and anxiety approximately 1 week before undergoing the TSST. These measures included the following:

Revised NEO Personality Inventory. The Revised NEO Personality Inventory (Costa and McCrae, 1992) is a 240item questionnaire developed through rational and factor analytic methods to measure the five major factors, or domains, of personality: Neuroticism (N), Extraversion (E), Openness to Experience (O), Agreeableness (A), and Conscientiousness (C). Each of the factors is represented by six facet subscales that provide a more 'fine-grained' analysis of specific traits than the higher-order factors. Items on the measure are answered on a 5-point Likert scale ranging from 'strongly agree' to 'strongly disagree'; scales are balanced to control for the effects of acquiescence. The items are simple statements describing general tendencies (eg 'It's often hard for me to make up my mind' or 'I often crave excitement'). Scores on the NEO are standardized by converting raw scores to $T$-scores; $T$-scores $<45$ are considered in the low range, those $45-55$ in the average range, and those $>55$ in the high range.

Brief Symptom Inventory. The Brief Symptom Inventory (BSI; Derogatis and Melisaratos, 1983) is a 53-item selfreport, clinical rating scale that provides scores on three global indices of psychological distress (ie Global Severity Index (GSI), Positive Symptom Total, and Positive Symptom Distress Index) and nine primary symptom dimensions (ie Somatization, Obsessive-Compulsive, Interpersonal Sensitivity, Depression, Anxiety, Hostility, Phobic Anxiety, Paranoid Ideation, and Psychoticism). The BSI is considered a measure of current psychological symptoms, rather than of personality. Respondents are asked to endorse how much they have been distressed or bothered during the past week by each of the described thoughts or feelings. Items are answered on a 5-point scale, ranging from 'not at all' to 'extremely'. Among the three global indices, the GSI represents the most sensitive single quantitative indicator of the respondent's overall psychological distress, reflecting information about both the number and severity of symptoms.

State-Trait Anxiety Inventory. The State-Trait Anxiety Inventory (STAI; Spielberger, 1983) is a 40 -item self-rating scale that measures state and trait anxiety. The state scale consists of 20 statements that evaluate the temporal or transitory feelings of anxiety. Respondents are asked to rate how they feel 'right now' or how they felt at a particular time in the recent past in response to simple statements, such as 'I feel at ease' or 'I am worried'. The intensity of their feelings is measured on a 4-point scale ranging from 'not at all' to 'very much so'. The trait scale consists of 20 similar statements that assess general anxiety levels or proneness. Respondents are instructed to rate how they generally feel in response to each of the items on a 4-point scale ranging from 'almost never' to 'almost always'.

\section{Hormone Assays}

Hormones were assayed as described previously (Blevins et al, 1994). Plasma concentrations of ACTH were assayed by a two-site IRMA (Nichols immunoradiometric assay). Intra-assay and interassay coefficients of variance were less than $9 \%$. Plasma concentrations of cortisol were measured by radioimmunoassay (Diagnostic Products Corporation, Inc., Los Angeles, CA). Intra-assay and interassay coefficients of variation were less than $7.5 \%$ and $9.0 \%$, respectively.

\section{Statistical Analysis}

Preliminary analyses included examination of gender differences in the demographic and clinical characteristics of interest using $t$-tests for continuous variables and $\chi^{2}$ tests for categorical variables. Mean baseline hormonal values were calculated by averaging the three levels obtained before the performance tasks were begun. Hormonal responses were summarized as peak, fold stimulation, and delta for preliminary examination of cortisol responses to the TSST. Peak was defined as the highest level reached after completion of the performance tasks. Fold stimulation was calculated as peak divided by baseline hormone levels. Delta was calculated as peak minus baseline. Differences between baseline and peak cortisol levels were evaluated with paired $t$-tests; relationships among the cortisol measures were examined with Pearson correlations. All cortisol measures were log transformed prior to inclusion in any of the analyses due to nonnormality.

For our primary analyses, we used longitudinal data analytic methods to examine relationships between NEO personality factor scores and cortisol levels. Specifically, we used linear regression with general estimating equations (GEE) to model cortisol responses as the dependent variable, accounting for within-subject correlation in cortisol levels over time. Based on examination of the data, we assumed that the structure of the within-subject correlation was autoregressive. The independent variables of interest were the NEO personality factor scores. Separate longitudinal models were run for each of the five NEO personality factors; additional models were run for the facet subscales when individual factors were found to be significantly associated with cortisol responses. Each of the models included terms to adjust for baseline cortisol, as well as linear and quadratic terms for time to account for the nonlinearity of the cortisol responses over time. We also included terms for mood (ie BSI GSI), trait anxiety, and race as effect modifiers, but the terms were removed when findings indicated that controlling for these factors did not meaningfully change our results. We evaluated the relevance of gender in the models by controlling for it and testing interactions between gender and each of the NEO factor scores. Owing to apparent interactions between gender and personality, we conducted post-hoc analyses to examine the models separately in each gender. Additional secondary analyses included examination of correlations between specific components of the cortisol time curve (ie baseline cortisol, peak response, fold stimulation, delta) and scores on the NEO personality factors with 
Table I Subject Characteristics ${ }^{a}$

\begin{tabular}{lccc}
\hline & Males & Females & P \\
\hline Sample size & 43 & 25 & \\
Age (years) & $21.7(2.8)$ & $21.4(2.8)$ & \\
& & & \\
Race, no. (\%) & & & 0.0209 \\
$\quad$ Caucasian & $34(79.1)$ & $15(60.0)$ & \\
African-American & $4(9.3)$ & $9(36.0)$ & \\
Asian & $5(11.6)$ & $1(4.0)$ & \\
& & & \\
Education (years) & $14.6(1.7)$ & $14.3(1.8)$ & \\
BSI Global Severity Index & $0.16(0.2)$ & $0.30(0.2)$ & 0.0148 \\
STAI Trait Anxiety & $28.7(7.6)$ & $33.3(8.2)$ & 0.0250 \\
NEO Neuroticism Factor & $43.8(8.4)$ & $45.4(8.6)$ & \\
NEO Extraversion Factor & $52.3(9.0)$ & $51.0(7.3)$ & \\
NEO Openness Factor & $52.6(9.2)$ & $57.4(12.4)$ & \\
NEO Agreeableness Factor & $49.7(9.8)$ & $46.7(11.6)$ & \\
NEO Conscientiousness Factor & $54.0(10.9)$ & $50.7(11.2)$ & \\
\hline
\end{tabular}

${ }^{a}$ Values represent means and standard deviations or absolute numbers.

Pearson coefficients. All analyses were carried out in STATA, version 8.0.

\section{RESULTS}

\section{Baseline Sample Characteristics}

Demographic characteristics of the sample are shown by gender in Table 1, along with mean scores on measures of mood, anxiety, and personality. Subjects were between 18 and 29 years of age, predominantly Caucasian $(70 \%)$ and male (63\%). Findings from mood, anxiety, and personality measures indicated that, as a group, subjects were not clinically depressed or anxious and scored in the 'average' range on the NEO personality factors ( $T$-scores). Racial composition differed between males and females. Although not clinically significant, females reported greater psychological distress and anxiety than males.

\section{Cortisol Responses to the TSST}

Findings showed that peak cortisol levels $(M=18.3$, $\mathrm{SD}=10.8)$ were significantly higher than baseline levels $(M=12.1, \mathrm{SD}=5.8)$ in the group as a whole $(t=6.79$; $p<0.0001)$, suggesting that the psychological stressor was effective in activating the physiological stress response. Significant positive correlations were observed between baseline and peak cortisol levels, indicating that subjects with higher pre-stress cortisol also had higher peak levels during the TSST than subjects with lower pre-stress cortisol $(r=0.563 ; p<0.0001)$. However, baseline cortisol levels were negatively associated with fold stimulation; subjects who had higher pre-stress cortisol levels had less relative change in levels than subjects whose initial levels were lower $(r=-0.289 ; p<0.017)$. Although also negative in direction, the relationship between baseline and delta cortisol levels was not statistically significant.

\section{Relationship between Personality and Cortisol}

Only scores on the NEO Openness factor were associated with cortisol responses to the TSST in the sample as a whole $(z=1.96 ; p=0.050)$; this relationship appeared to be accounted for almost exclusively by scores on the Actions $(z=2.33 ; p=0.020)$ and Ideas $(z=2.74 ; p=0.006)$ facets. No interactions were observed between Openness and gender. However, significant interactions were observed between gender and personality in the factor-level longitudinal models that included terms for either Neuroticism or Extraversion. Findings from subsequent analyses in which the data were stratified by gender showed that Neuroticism scores were negatively associated with cortisol responses to the TSST in females, but not in males. In contrast, Extraversion scores were positively associated with cortisol responses to the TSST in males, but not in females. Results of the factor-level and facet-level longitudinal analyses for the Neuroticism and Extraversion domains are shown in Tables 2 and 3, respectively. In females, the negative relationship between Neuroticism and cortisol appeared to be the result of scores on the associated facets of Anxiety, Anger Hostility, Depression, and SelfConsciousness. In males, the positive relationship between Extraversion and cortisol responses was accounted for primarily by scores on the associated facets of Warmth, Activity, and Positive Emotions. Scores on the factors of Agreeableness and Conscientiousness were not associated with cortisol responses to the TSST.

We then deconstructed the cortisol-time curve into component parts: baseline cortisol, peak cortisol, fold stimulation (peak/baseline), and delta (peak minus baseline). When each component was analyzed for association with the NEO factors, only fold stimulation and delta were correlated with Neuroticism and Extraversion. In females, a negative relationship was found between fold stimulation and scores on the Neuroticism factor $(r=-0.389$; $p=0.061$ ), primarily accounted for by associations between cortisol and the NEO facets of Depression $(r=-0.546$; $p=0.005)$ and Self-Consciousness $(r=-0.421 ; p=0.036)$. The relationship between Depression and cortisol fold stimulation in females is shown in Figure 1. In males, the only personality factor that was found to be associated with fold stimulation was Extraversion $(r=0.310 ; p=0.043)$. This relationship appeared to be accounted for primarily by scores on the facets of Warmth $(r=0.330 ; p=0.031)$, Activity $(r=0.396 ; p=0.009)$, and Positive Emotions $(r=0.2933 ; p=0.056)$. The relationship between Warmth and cortisol fold stimulation in males is shown in Figure 2. A trend was observed for a positive association between Openness and cortisol fold stimulation in females $(r=0.3867 ; p=0.0620)$. Findings for delta mirrored those for fold stimulation and are not reported.

\section{DISCUSSION}

The results of this study replicate those of prior investigations showing that the TSST provokes increases in cortisol levels and is a useful laboratory tool for measuring individual differences in responses to psychological stress. Our results further show that differences in response to psychological stress are associated with differences in 
Table 2 Relationship between Neuroticism and Cortisol TSST Responses Over Time*

\begin{tabular}{|c|c|c|c|c|}
\hline & $\begin{array}{l}\text { Sex-adjusted } \\
\text { models } \\
z(p)\end{array}$ & $\begin{array}{c}\text { Sex-by-trait interaction } \\
\text { models } \\
z(p)\end{array}$ & $\begin{array}{c}\text { Males only } \\
\text { z (p) }\end{array}$ & $\begin{array}{c}\text { Females only } \\
z(p)\end{array}$ \\
\hline Neuroticism & 0.18 (0.857) & $1.46(0.144)$ & $1.46(0.145)$ & $-2.11(0.035)$ \\
\hline Sex & $-2.99(0.003)$ & $1.86(0.068)$ & - & - \\
\hline Sex*Neuroticism & - & $-2.65(0.008)$ & - & - \\
\hline Sex & $-3.08(0.002)$ & $1.48(0.139)$ & - & - \\
\hline Sex*Anxiety & - & $-2.27(0.023)$ & - & - \\
\hline Anger Hostility (N2) & $-1.31(0.189)$ & $0.11(0.912)$ & $0.12(0.907)$ & $-2.00(0.045)$ \\
\hline Sex & $-2.70(0.007)$ & $0.64(0.525)$ & - & - \\
\hline Sex*Anger & - & $-1.38(0.168)$ & - & - \\
\hline Sex & $-2.96(0.003)$ & $1.23(0.218)$ & - & - \\
\hline Sex*Self-conscious & - & $-2.02(0.044)$ & - & - \\
\hline Impulsiveness (N5) & $0.93(0.35 \mathrm{I})$ & $1.23(0.217)$ & $1.23(0.219)$ & $0.06(0.955)$ \\
\hline Sex & $-3.72(0.000)$ & $0.35(0.723)$ & - & - \\
\hline Sex*Impulsiveness & - & $-0.90(0.368)$ & - & - \\
\hline Vulnerability (N6) & $-0.14(0.886)$ & $0.49(0.624)$ & $0.49(0.621)$ & $-0.93(0.354)$ \\
\hline Sex & $-3.11(0.002)$ & $0.40(0.69)$ & - & - \\
\hline Sex*Vulnerability & - & $-1.09(0.276)$ & - & - \\
\hline
\end{tabular}

* Separate models were conducted for the Neuroticism factor and each of the facet subscales.

Each model also includes terms for baseline cortisol, time, and time 2 .

certain personality traits. In the sample as a whole, subjects who scored lower on the personality dimension of Openness had lower cortisol responses to the TSST than subjects who scored higher on this dimension. Generally, high scores on the Openness factor signify qualities that are reflective of healthy psychological functioning, including aesthetic sensitivity, attentiveness to inner feelings, preferences for variety, intellectual curiosity, and independence of judgment. We also found that cortisol responses to the TSST corresponded to some personality dimensions in a genderspecific manner. In women, blunted cortisol responses were associated with higher scores on the Neuroticism factor, as well as with higher scores on four of its facets (Anxiety, Anger, Hostility, Depression, and Self-Consciousness). In men, blunted cortisol responses were associated with lower scores on the Extraversion factor, as well as with lower scores on three of its facets (Warmth, Activity, and Positive Emotion). Thus, personality traits that have traditionally been associated with greater psychopathology were found to be associated with blunted HPA axis responses to stress. These data are consistent with the literature showing that some depressives, as well as individuals with lower selfesteem, less hardiness, or lower perceived sense of control, have lower basal and/or provoked adrenocortical activity than individuals without these characteristics (Brandtstadter et al, 1991; Grossi et al, 1998; Zorrilla et al, 1995).

Within the field of biological psychiatry, findings of hypocortisolism have been most prominently associated with post-traumatic stress disorder (PTSD) (Yehuda, 1997). However, it has become apparent in recent years that hypocortisolism is not a specific correlate of PTSD, but may be more pervasively linked to a number of stress-related disorders (Heim et al, 2000). Our findings extend a growing body of literature showing that such alterations in HPA axis dynamics may also be associated with personality. For example, McCleery and Goodwin (2001) demonstrated that individuals with high neuroticism have blunted cortisol responses to the combined dexamethasone-corticotropinreleasing hormone test as compared to individuals with low neuroticism. Portella et al (2005) found that higher neuroticism is associated with enhanced morning salivary cortisol levels. Neuroticism has also been negatively associated with plasma cortisol levels obtained after a light mid-day meal, whereas extraversion was positively associated with these levels (LeBlanc and Ducharme, 2005). Studies using laboratory methods of inducing psychological stress have produced similar findings. For example, Phillips et al (2005) reported that neuroticism was associated with blunted cortisol responsivity to a mental arithmetic task. Blunted cortisol responses to stress have also been associated with high somatic anxiety, high depression, and a low sense of mastery (Grossi et al, 1998).

There is evidence that personality characteristics may influence affective reactions to stress and other naturally occurring events. Individuals with high neuroticism have been reported to have higher levels of anger and depression 
Table 3 Relationship Between Extraversion and Cortisol TSST Responses Over Time

\begin{tabular}{|c|c|c|c|c|}
\hline & $\begin{array}{l}\text { Sex-adjusted } \\
\text { models } \\
z(p)\end{array}$ & $\begin{array}{c}\text { Sex-by-trait interaction } \\
\text { models } \\
z(p)\end{array}$ & $\begin{array}{l}\text { Males only } \\
\qquad z(p)\end{array}$ & $\begin{array}{c}\text { Females only } \\
z(p)\end{array}$ \\
\hline Extraversion & $0.62(0.539)$ & $1.97(0.048)$ & $2.07(0.039)$ & $-1.72(0.086)$ \\
\hline Sex & $-2.96(0.003)$ & $1.75(0.08 \mid)$ & - & - \\
\hline Sex*Extraversion & - & $-2.39(0.017)$ & - & - \\
\hline Sex*Warmth & - & $-0.97(0.334)$ & - & - \\
\hline Gregariousness (E2) & $-0.39(0.695)$ & $0.25(0.799)$ & $0.35(0.727)$ & $-1.11(0.268)$ \\
\hline Sex & $-3.23(0.00 \mathrm{I})$ & $0.23(0.819)$ & - & - \\
\hline Sex*Gregariousness & - & $-0.86(0.392)$ & - & - \\
\hline Sex & $-2.55(0.011)$ & $0.86(0.390)$ & - & - \\
\hline Sex*Activity & - & $-1.41(0.158)$ & - & - \\
\hline Excitement (E5) & $-1.47(0.14 I)$ & $-0.05(0.961)$ & $0.20(0.84 I)$ & $-4.39(0.000)$ \\
\hline Sex & $-3.30(0.00 \mathrm{I})$ & $2.24(0.025)$ & - & - \\
\hline Sex*Excitement & - & $-3.12(0.002)$ & - & - \\
\hline Positive Emotion (E6) & $2.00(0.046)$ & 2.35 (0.019) & $2.36(0.018)$ & $0.21(0.835)$ \\
\hline Sex & $-3.07(0.002)$ & $0.16(0.873)$ & - & - \\
\hline Sex*Positive Emotion & - & $-0.76(0.447)$ & - & - \\
\hline
\end{tabular}

* Separate models were conducted for the Extraversion factor and each of the facet subscales.

Each model also includes terms for baseline cortisol, time, and time ${ }^{2}$.

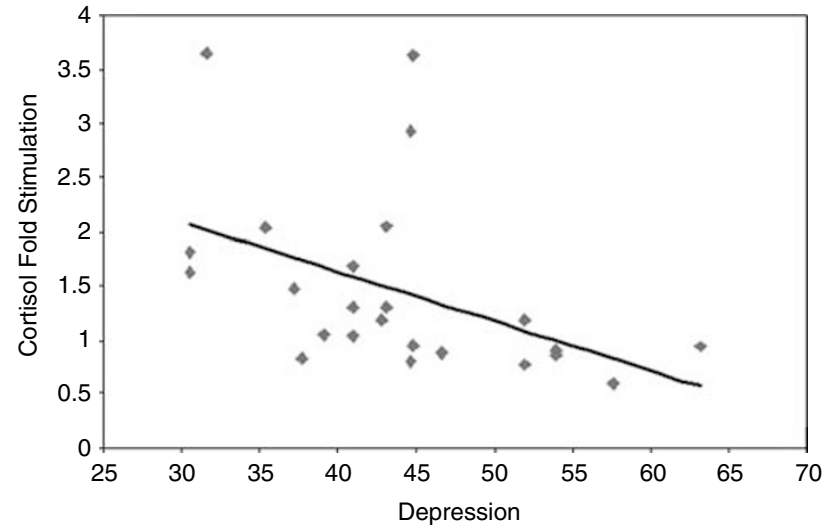

Figure I Scatterplot showing the negative correlation between TSST cortisol fold stimulation (peak/baseline) scores and scores on the NEO personality facet of Depression in females.

when faced with interpersonal conflict than individuals with low neuroticism (Bolger and Zuckerman, 1995), as well as larger increases in anxiety in response to stressful events (Bolger, 1990). Personality researchers have long maintained that neuroticism is a vulnerability marker for depression and other comorbid psychiatric disorders (Khan et al, 2005; Ormel et al, 2004). Interestingly, blunted cortisol responses to stress have been observed in depressed patients (Gotthardt et al, 1995; Grof et al, 1982; Kathol

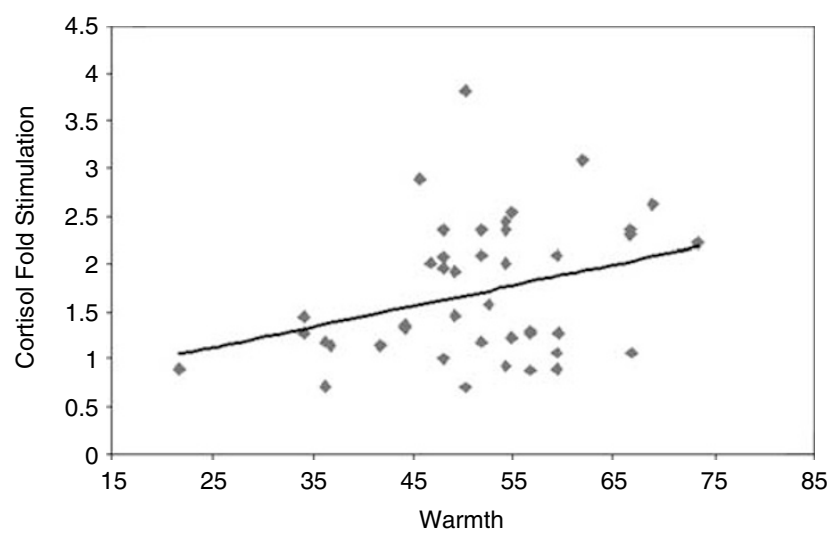

Figure 2 Scatterplot showing the positive correlation between TSST cortisol fold stimulation (peak/baseline) scores and scores on the NEO personality facet of Warmth in males.

et al, 1992; Lopez et al, 1987; Young et al, 2000), as well as in healthy adults with high trait anxiety (Jezova et al, 2004). Our findings showing that higher Neuroticism scores are associated with blunted cortisol responses to stress in nondepressed women suggest that these women may be at increased risk for depression by virtue of their temperament and/or stress response. Although we did not observe the same relationship in men, it should be noted that rates of both depression and neuroticism are higher in women than 
in men (Costa et al, 2001; Gater et al, 1998; Takkinen et al, 2004). Findings from one recent study showed that neuroticism may moderate the association between female gender and depression (Goodwin and Gotlib, 2004). However, it is equally important to note that our subjects have no past or current history of depression, suggesting that a blunted cortisol response to stressors may represent a risk factor for, rather than a consequence of, depression.

Abnormal HPA axis activity has been observed in the first-degree relatives of depressed patients who have not experienced depression (Holsboer et al, 1995). It is possible that this abnormal hormonal response is inherited as part of the trait of neuroticism and/or extraversion. There is evidence that temperament and personality, including neuroticism and extraversion, have a substantial heritable component (Bouchard and McGue, 2003; Jang et al, 1996) and may account for as much as $30-60 \%$ of the observed variance of such traits (Loehlin, 1993). Similarly, cortisol responses to stress show significant heritability (Federenko et al, 2004). Both HPA axis dysfunction and temperamental features, such as high Neuroticism and low Extraversion, may be important risk factors for depression. Whether these vulnerabilities are independent factors or whether they are different manifestations of the same characteristic requires further investigation. Nevertheless, the role of neuroticism in depression remains controversial. Several authors have proposed that scores on measures of Neuroticism reflect a person's current or characteristic level of distress, rather than signaling liability for depression (Farmer et al, 2002; Katz and McGuffin, 1987; Ormel et al, 2004).

Our results suggest that blunted cortisol responses to the TSST are associated with different personality constellations in men than they are in women. This finding may be attributable to gender differences in the appreciation of stress, in the biological response to stress, or in specific adaptations to stress that may influence personality development. There is prior evidence of functional differences in the HPA axis of men and women (Kirschbaum et al, 1999; Kudielka et al, 2004; Stroud et al, 2002). It is conceivable that this function is related to biological differences that are manifest in the personality attributes. In a genomewide linkage scan of neuroticism, a region on chromosome $6 \mathrm{p}$ was identified with a LOD score of 3.9 in male-male sibling pairs, while the same region had almost no signal in female-female pairs (Nash et al, 2004). If this finding were to lead to the cloning of a sex-specific neuroticism gene, it would be possible to construe that the biological basis for personality domains may be different in the sexes and that this difference may influence the relationship of stress to the HPA axis. Finally, the stress response may have a profound impact developmentally on the development of personality. This impact may interact with other gender-related factors, with the result of fostering the development of different personality attributes in males and females.

The present study has several weaknesses. First, we conducted a number of analyses without correction for multiple comparisons, meaning that the findings may be subject to type I errors. Nevertheless, since examination of the relationship between cortisol dynamics and personality is still exploratory, we believe that false-negative results may be as important as false-positive results. Multiple compar- ison methods, such as the Bonferroni correction, tend to be overly stringent in such cases. It would have been ideal to have a larger sample size and further replication of these findings is essential. Second, since our sample consisted of only young, healthy adults, it cannot be assumed that the findings will generalize to populations of adults with different demographic or psychobiological characteristics. One should also be cautious about generalizing the pattern of responses seen in artificial settings to real-life situations. Although race could have been a confounder as previously described by Yanovski et al (2000), adjusting for race did not meaningfully change the results of our statistical analyses; so race was not included as a factor in the final models. Finally, our study does not shed light on why associations between cortisol and personality varied by gender.

In summary, we found that personality traits that have traditionally been associated with greater psychopathology are also associated with blunted HPA axis responses to stress. We also found that cortisol responses to a laboratory-based, psychological stress test correspond to specific personality dimensions in a gender-specific manner. In women, blunted cortisol responses were associated with higher Neuroticism scores. By contrast, in men, blunted cortisol responses were associated with lower Extraversion scores. Further work needs to be carried out to determine the mechanistic relationship between cortisol responses to stress and dimensions of personality.

\section{ACKNOWLEDGEMENTS}

This work was supported by NIH grants R01 AA10158, F32 AA013681, and M01 RR00052 (GCRC) and a generous gift from the Kenneth Lattman Foundation (GSW).

\section{REFERENCES}

Abelson JL, Curtis GC (1996). Hypothalamic-pituitary-adrenal axis activity in panic disorder. 24-hour secretion of corticotropin and cortisol. Arch Gen Psychiatry 53: 323-331.

Altemus M, Pigott T, Kalogeras KT, Demitrack M, Dubbert B, Murphy DL et al (1992). Abnormalities in the regulation of vasopressin and corticotropin releasing-factor secretion in obsessive-compulsive disorder. Arch General Psychiatry 49: 9-20.

Anisman H, Ravindran AV, Griffiths J, Merali Z (1999). Endocrine and cytokine correlates of major depression and dysthymia with typical or atypical features. Mol Psychiatry 4: 182-188.

Arborelius L, Owens MJ, Plotsky PM, Nemeroff CB (1999). The role of corticotropin-releasing factor in depression and anxiety disorders. J Endocrinol 160: 1-12.

Arnetz BB, Fjellner B (1986). Psychological predictors of neuroendocrine responses to mental stress. J Psychosom Res 30: 297-305.

Barden N (2004). Implication of the hypothalamic-pituitaryadrenal axis in the physiopathology of depression. J Psychiatry Neurosci 29: 185-193.

Bienvenu OJ, Nestadt G, Samuels JF, Costa PT, Howard WT, Eaton WW (2001). Phobic, panic, and major depressive disorders and the five-factor model of personality. J Nerv Ment Dis 189: 154161.

Bienvenu OJ, Samuels JF, Costa PT, Reti IM, Eaton WW, Nestadt G (2004). Anxiety and depressive disorders and the five-factor model of personality: a higher- and lower-order personality trait investigation in a community sample. Depress Anxiety 20: 92-97. 
Blevins Jr LS, Dobs AS, Wand GS (1994). Naloxone-induced activation of the hypothalamic-pituitary-adrenal axis in suspected central adrenal insufficiency. $A m$ J Med Sci 308: 167-170.

Bolger N (1990). Coping as a personality process: a prospective study. J Pers Soc Psychol 59: 525-537.

Bolger N, Zuckerman A (1995). A framework for studying personality in the stress process. J Pers Soc Psychol 69: 890-902.

Bouchard Jr TJ, McGue M (2003). Genetic and environmental influences on human psychological differences. J Neurobiol 54: 4-45.

Brandtstadter J, Baltes-Gotz B, Kirschbaum C, Hellhammer D (1991). Developmental and personality correlates of adrenocortical activity as indexed by salivary cortisol: observations in the age range of 35 to 65 years. J Psychosom Res 35: 173-185.

Bucholz KK, Cadoret R, Cloninger CR, Dinwiddie SH, Hesselbrock VM, Nurnberger Jr JI et al (1994). A new, semi-structured psychiatric interview for use in genetic linkage studies: a report on the reliability of the SSAGA. J Stud Alcohol 55: 149-158.

Carroll BJ (1982). Clinical applications of the dexamethasone suppression test for endogenous depression. Pharmacopsychiatria 15: 19-25.

Coryell W, Noyes R, Reich J (1991). The prognostic-significance of Hpa-axis disturbance in panic disorder - a 3-year follow-up. Biol Psychiatry 29: 96-102.

Costa P, McCrae R (1992). Revised NEO Personality Inventory (NEO-PI-R) and NEO Five-Factor Inventory (NEO-FFI) Professional Manual. Psychological Assessment Resources: Odessa, FL.

Costa Jr PT, Terracciano A, McCrae RR (2001). Gender differences in personality traits across cultures: robust and surprising findings. J Pers Soc Psychol 81: 322-331.

Derogatis LR, Melisaratos N (1983). The Brief Symptom Inventory-An Introductory Report. Psychol Med 13: 595-605.

Farmer A, Redman K, Harris T, Mahmood A, Sadler S, Pickering A et al (2002). Neuroticism, extraversion, life events and depression. The Cardiff Depression Study. Br J Psychiatry 181: 118-122.

Federenko IS, Nagamine M, Hellhammer DH, Wadhwa PD, Wust S (2004). The heritability of hypothalamus pituitary adrenal axis responses to psychosocial stress is context dependent. J Clin Endocrinol Metab 89: 6244-6250.

Furlan PM, DeMartinis N, Schweizer E, Rickels K, Lucki I (2001). Abnormal salivary cortisol levels in social phobic patients in response to acute psychological but not physical stress. Biol Psychiatry 50: 254-259.

Gater R, Tansella M, Korten A, Tiemens BG, Mavreas VG, Olatawura MO (1998). Sex differences in the prevalence and detection of depressive and anxiety disorders in general health care settings: report from the World Health Organization Collaborative Study on Psychological Problems in General Health Care. Arch Gen Psychiatry 55: 405-413.

Geracioti Jr TD, Loosen PT, Orth DN (1997). Low cerebrospinal fluid corticotropin-releasing hormone concentrations in eucortisolemic depression. Biol Psychiatry 42: 165-174.

Gold PW, Chrousos GP (2002). Organization of the stress system and its dysregulation in melancholic and atypical depression: high vs low CRH/NE states. Mol Psychiatry 7: 254-275.

Goodwin RD, Gotlib IH (2004). Gender differences in depression: the role of personality factors. Psychiatry Res 126: 135-142.

Gotthardt U, Schweiger U, Fahrenberg J, Lauer CJ, Holsboer F, Heuser I (1995). Cortisol, ACTH, and cardiovascular response to a cognitive challenge paradigm in aging and depression. Am J Physiol 268: R865-R873.

Grof E, Brown GM, Grof P (1982). Prolactin response to hypoglycemia in acute depression. Prog Neuropsychopharmacol Biol Psychiatry 6: 487-490.

Grossi G, Ahs A, Lundberg U (1998). Psychological correlates of salivary cortisol secretion among unemployed men and women. Integr Physiol Behav Sci 33: 249-263.
Heim C, Ehlert U, Hellhammer DH (2000). The potential role of hypocortisolism in the pathophysiology of stress-related bodily disorders. Psychoneuroendocrinology 25: 1-35.

Hirschfeld RM, Klerman GL, Lavori P, Keller MB, Griffith P, Coryell W (1989). Premorbid personality assessments of first onset of major depression. Arch Gen Psychiatry 46: 345-350.

Holsboer F (2000). The corticosteroid receptor hypothesis of depression. Neuropsychopharmacology 23: 477-501.

Holsboer F, Barden N (1996). Antidepressants and hypothalamicpituitary-adrenocortical regulation. Endocr Rev 17: 187-205.

Holsboer F, Lauer CJ, Schreiber W, Krieg JC (1995). Altered hypothalamic-pituitary-adrenocortical regulation in healthy subjects at high familial risk for affective disorders. Neuroendocrinology 62: 340-347.

Hubert W, Jong-Meyer R (1992). Saliva cortisol responses to unpleasant film stimuli differ between high and low trait anxious subjects. Neuropsychobiology 25: 115-120.

Jang KL, Livesley WJ, Vernon PA, Jackson DN (1996). Heritability of personality disorder traits: a twin study. Acta Psychiatr Scand 94: $438-444$.

Jezova D, Makatsori A, Duncko R, Moncek F, Jakubek M (2004). High trait anxiety in healthy subjects is associated with low neuroendocrine activity during psychosocial stress. Prog Neuropsychopharmacol Biol Psychiatry 28: 1331-1336.

Kara S, Yazici KM, Gulec C, Unsal I (2000). Mixed anxietydepressive disorder and major depressive disorder: comparison of the severity of illness and biological variables. Psychiatry Res 94: 59-66.

Kathol RG, Gehris TL, Carroll BT, Samuelson SD, Pitts AF, Meller WH et al (1992). Blunted ACTH response to hypoglycemic stress in depressed patients but not in patients with schizophrenia. J Psychiatr Res 26: 103-116.

Katz R, McGuffin P (1987). Neuroticism in familial depression. Psychol Med 17: 155-161.

Kendler KS, Neale MC, Kessler RC, Heath AC, Eaves LJ (1993). A longitudinal twin study of personality and major depression in women. Arch Gen Psychiatry 50: 853-862.

Khan AA, Jacobson KC, Gardner CO, Prescott CA, Kendler KS (2005). Personality and comorbidity of common psychiatric disorders. Br J Psychiatry 186: 190-196.

Kirschbaum C, Bartussek D, Strasburger CJ (1992). Cortisol responses to psychological stress and correlations with personality-traits. Person Indiv Differ 13: 1353-1357.

Kirschbaum C, Kudielka BM, Gaab J, Schommer NC, Hellhammer DH (1999). Impact of gender, menstrual cycle phase, and oral contraceptives on the activity of the hypothalamus-pituitaryadrenal axis. Psychosom Med 61: 154-162.

Kirschbaum C, Pirke KM, Hellhammer DH (1993). The 'Trier Social Stress Test' - a tool for investigating psychobiological stress responses in a laboratory setting. Neuropsychobiology 28: 76-81.

Kudielka BM, Buske-Kirschbaum A, Hellhammer DH, Kirschbaum C (2004). HPA axis responses to laboratory psychosocial stress in healthy elderly adults, younger adults, and children: impact of age and gender. Psychoneuroendocrinology 29: 83-98.

LeBlanc J, Ducharme MB (2005). Influence of personality traits on plasma levels of cortisol and cholesterol. Physiol Behav 84: 677-680.

Linkowski P (2003). Neuroendocrine profiles in mood disorders. Int J Neuropsychopharmacol 6: 191-197.

Loehlin JC (1993). Nature, nurture, and conservatism in the Australian Twin Study. Behav Genet 23: 287-290.

Lopez JF, Kathol RG, Jaeckle RS, Meller W (1987). The HPA axis response to insulin hypoglycemia in depression. Biol Psychiatry 22: $153-166$.

McCleery JM, Goodwin GM (2001). High and low neuroticism predict different cortisol responses to the combined dexamethasone-CRH test. Biol Psychiatry 49: 410-415. 
Modell S, Lauer CJ, Schreiber W, Huber J, Krieg JC, Holsboer F (1998). Hormonal response pattern in the combined DEX-CRH test is stable over time in subjects at high familial risk for affective disorders. Neuropsychopharmacology 18: 253-262.

Nash MW, Huezo-Diaz P, Williamson RJ, Sterne A, Purcell S, Hoda $\mathrm{F}$ et al (2004). Genome-wide linkage analysis of a composite index of neuroticism and mood-related scales in extreme selected sibships. Hum Mol Genet 13: 2173-2182.

Ormel J, Rosmalen J, Farmer A (2004). Neuroticism: a noninformative marker of vulnerability to psychopathology. Soc Psychiatry Psychiatr Epidemiol 39: 906-912.

Owens MJ, Nemeroff CB (1993). The role of corticotropin-releasing factor in the pathophysiology of affective and anxiety disorders: laboratory and clinical studies. Ciba Found Symp 172: 296-308.

Phillips AC, Carroll D, Burns VE, Drayson M (2005). Neuroticism, cortisol reactivity, and antibody response to vaccination. Psychophysiology 42: 232-238.

Portella MJ, Harmer CJ, Flint J, Cowen P, Goodwin GM (2005). Enhanced early morning salivary cortisol in neuroticism. Am J Psychiatry 162: 807-809.

Pruessner JC, Gaab J, Hellhammer DH, Lintz D, Schommer N, Kirschbaum C (1997). Increasing correlations between personality traits and cortisol stress responses obtained by data aggregation. Psychoneuroendocrinology 22: 615-625.

Roy-Byrne PP, Uhde TW, Post RM, Gallucci W, Chrousos GP, Gold PW (1986). The corticotropin-releasing hormone stimulation test in patients with panic disorder. Am J Psychiatry 143: 896-899.

Salmon P, Pearce S, Smith CC, Manyande A, Heys A, Peters N et al (1989). Anxiety, type A personality and endocrine responses to surgery. Br J Clin Psychol 28(Part 3): 279-280.

Samuels J, Eaton WW, Bienvenu OJ, Brown CH, Costa PT, Nestadt $\mathrm{G}$ (2002). Prevalence and correlates of personality disorders in a community sample. Br J Psychiatry 180: 536-542.

Schommer NC, Kudielka BM, Hellhammer DH, Kirschbaum C (1999). No evidence for a close relationship between personality traits and circadian cortisol rhythm or a single cortisol stress response. Psychol Rep 84: 840-842.
Schreiber W, Lauer CJ, Krumrey K, Holsboer F, Krieg JC (1996). Dysregulation of the hypothalamic-pituitary-adrenocortical system in panic disorder. Neuropsychopharmacology 15: 7-15.

Spielberger C (1983). State-Trait Anxiety Inventory (STAI). Mind Garden: Palo Alto, CA.

Stroud LR, Salovey P, Epel ES (2002). Sex differences in stress responses: social rejection versus achievement stress. Biol Psychiatry 52: 318-327.

Takkinen S, Gold C, Pedersen NL, Malmberg B, Nilsson S, Rovine M (2004). Gender differences in depression: a study of older unlike-sex twins. Aging Ment Health 8: 187-195.

Tsigos C, Chrousos GP (2002). hypothalamic-pituitary-adrenal axis, neuroendocrine factors and stress. J Psychosom Res 53: 865-871.

van Eck MM, Nicolson NA, Berkhof H, Sulon J (1996). Individual differences in cortisol responses to a laboratory speech task and their relationship to responses to stressful daily events. Biol Psychol 43: 69-84.

Wedekind D, Bandelow B, Broocks A, Hajak G, Ruther E (2000). Salivary, total plasma and plasma free cortisol in panic disorder. J Neural Transm 107: 831-837.

Yanovski JA, Yanovski SZ, Boyle AJ, Gold PW, Sovik KN, Sebring NG et al (2000). Hypothalamic-pituitary-adrenal axis activity during exercise in African American and Caucasian women. $J$ Clin Endocrinol Metab 85: 2660-2663.

Yehuda R (1997). Sensitization of the hypothalamic-pituitaryadrenal axis in posttraumatic stress disorder. Ann NY Acad Sci 821: $57-75$.

Young EA, Abelson JL, Cameron OG (2004). Effect of comorbid anxiety disorders on the hypothalamic-pituitary-adrenal axis response to a social stressor in major depression. Biol Psychiatry 56: $113-120$.

Young EA, Lopez JF, Murphy-Weinberg V, Watson SJ, Akil H (2000). Hormonal evidence for altered responsiveness to social stress in major depression. Neuropsychopharmacology 23: 411-418.

Zorrilla EP, DeRubeis RJ, Redei E (1995). High self-esteem, hardiness and affective stability are associated with higher basal pituitary-adrenal hormone levels. Psychoneuroendocrinology 20: 591-601. 